\title{
En altertavles tilblivelse
}

\section{Af Else-Marie Boyhus.}

Kildematerialet til belysning af inventaret i vore kirker er desværre så sparsomt, at de arkivalske studier i mange tilfælde kun bliver supplement til unders $\varnothing$ gelsen og beskrivelsen af inventaret på stedet. De to vigtigste grupper inden for kirkearkivalierne er kirkeregnskabsb $\phi$ ger og bilag til kirkeregnskaberne. Regnskabsb $\phi$ gerne er normalt ret kortfattede, men giver $i$ langt de fleste tilfælde sikre oplysninger. Bilagenes kvalitet svinger derimod meget, de indeholder i heldigste tilfælde licitationsbetingelser, overslag, udkast til kontrakter, kontrakter og kvitteringer; men de tilfælde, hvor man til belysning af en reparation eller en nyanskaffelse $i$ en kirke har både regnskab og fyldige bilag, er forsvindende få. Derfor hører det til undtagelserne, at man - som i dette tilfælde - kan tage sit udgangspunkt $i$ arkivstudierne ${ }^{1}$.

1703 oplyser Sottrup kirkeregnskabsbog², at der er betalt 400 mark til billedhugger Peter Petersen i T $\varnothing$ nder $^{3}$ for kirkens nye alter, maleren i Tønder får $\mathbf{2 0 0}$ mark for stafferingen.

1781 indgives der klage over fugtigheden $i$ kirken ${ }^{4}$, meget træværk er angrebet af svamp, og det er især gået hårdt ud over altertavlen, hvis topstykke og fløje er meget $l \varnothing$ se. Året efter ${ }^{5}$ oplyses, at fløjene er angrebet af orm, kun selve tavlen og de to piller er friske. Samme år beslutter man sig til at anskaffe en ny altertavle, og licitationsbetingelserne for arbejdet opstilles. Det gamle alter skal helt nedbrydes, dog skal selve tavlen og de to piller genanvendes. Punkt VI i betingelserne hedder ${ }^{5}$ : An dem neuen Altar zu beyden Seiten und oben, neue Verziehrunge von frischem Eichen Holz gemacht, wozu der Riss in Termino eingeliefert werden wird. Die Verziehrunge werden verguldet, die Pfeiler mit Farben marmorirt und die Tafel mit der Kreuzigung Christi nach dem angelegten Kupfer, fein und sauber gemahlt.* Som en tilf $\varnothing j$ jelse til licitationsbetingelserne gøres opmærksom på, at arbejdet skal udf $\varnothing$ res i overensstemmelse »mit unserm Pettschaften Riss «. Arbejdet overdrages snedker Christensen fra Sottrup, og 1783 står der i kirkeregnskabsbogen, at han fik 134 rigsdaler for det nye alter. 


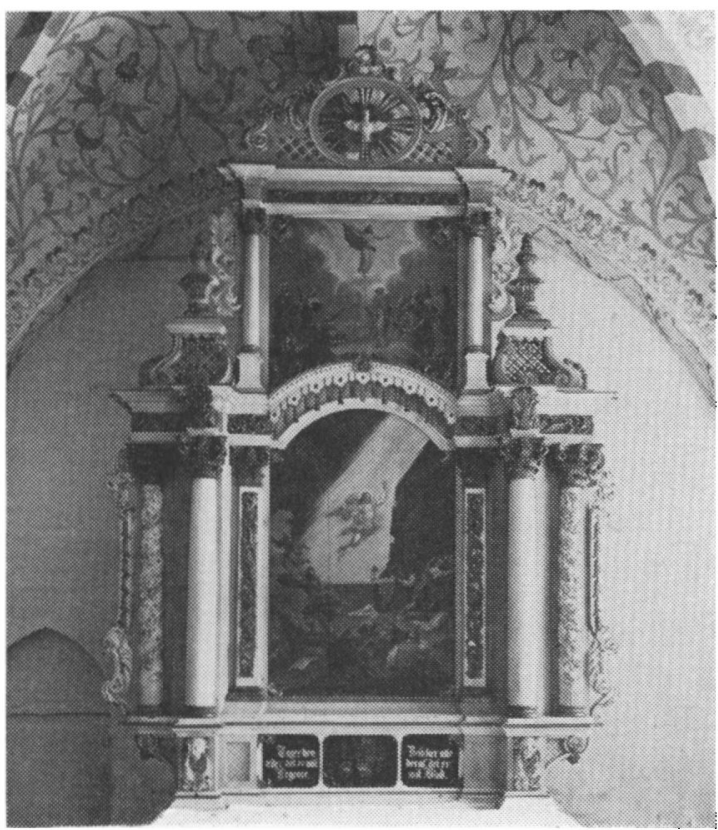

Fig. 1. Altret i Sottrup kirke pá Sundeved.

Her ser vi altså fremgangsmåden: Snedkeren får af kirken udleveret en signeret skitse ( $\gg$ Pettschaften Riss $\ll$ ), som skal ligge til grund for en arbejdstegning, der skal indleveres til kirken, $f \phi r$ det egentlige arbejde påbegyndes (»wozu der Riss in Termino eingeliefert werden wird $\ll$ ). Samtidig får maleren udleveret et kobberstik, som skal fungere som forlæg for tavlens maleri (herom senere).

Nu er det så heldigt, at forlæggene såvel for den nye altertavle som for maleriet $\mathrm{i}$ storfeltet samt snedkerens arbejdstegning er bevaret ved sagens akter $i$ arkivet ${ }^{5}$.

Den signerede skitse af selve altertavlen, som kirken har udleveret til snedkeren, er et kobberstik (fig. 2), der viser to alternative forslag til en altertavle i pomp $\phi$ s rokokko. Det er tegnet og stukket af I. G. Koenig7, udgivet af Georg Hertel, det bærer forlagsnummeret $88 \mathrm{og}$ er nummer $3 \mathrm{i}$ en serie på ialt fire stik ${ }^{8}$. $P a ̊$ grundlag af dette stik har snedker Christensen udf $\varnothing$ rt sin 


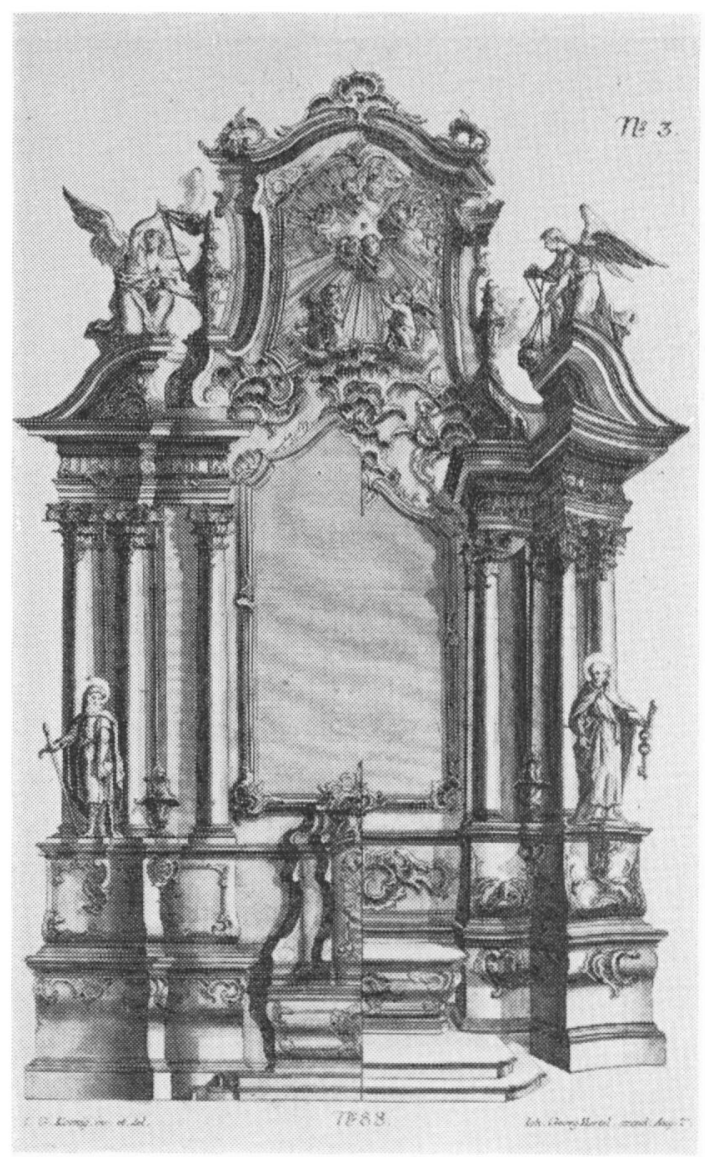

Fig. 2.

Kobberstukket forlu'! for altertavlen.

arbejdstegning (fig. 3). Som man ser, har han ikke slavisk kopieret stikket, og hans arbejdstegning kan karakteriseres som en forenklet reproduktion med nye stil-elementer. Louis Seizestilen, der krævede st $\varnothing$ rre enkelhed og regelmæssigere linjef $\phi r i n g$, havde nu holdt sit indtog. Men det er ikke meget af det nye, snedker Christensen har turdet tage med: Vasernes form, frisen over storfeltet og de s-svungne blade med de beskedne guirlander under de yderste s $\varnothing j$ ler er alt. Fra forlægget har han beholdt det svungne topstykke, gavlvolutterne og de forskudte $s \emptyset j l e s t i l l i n g e r$, 


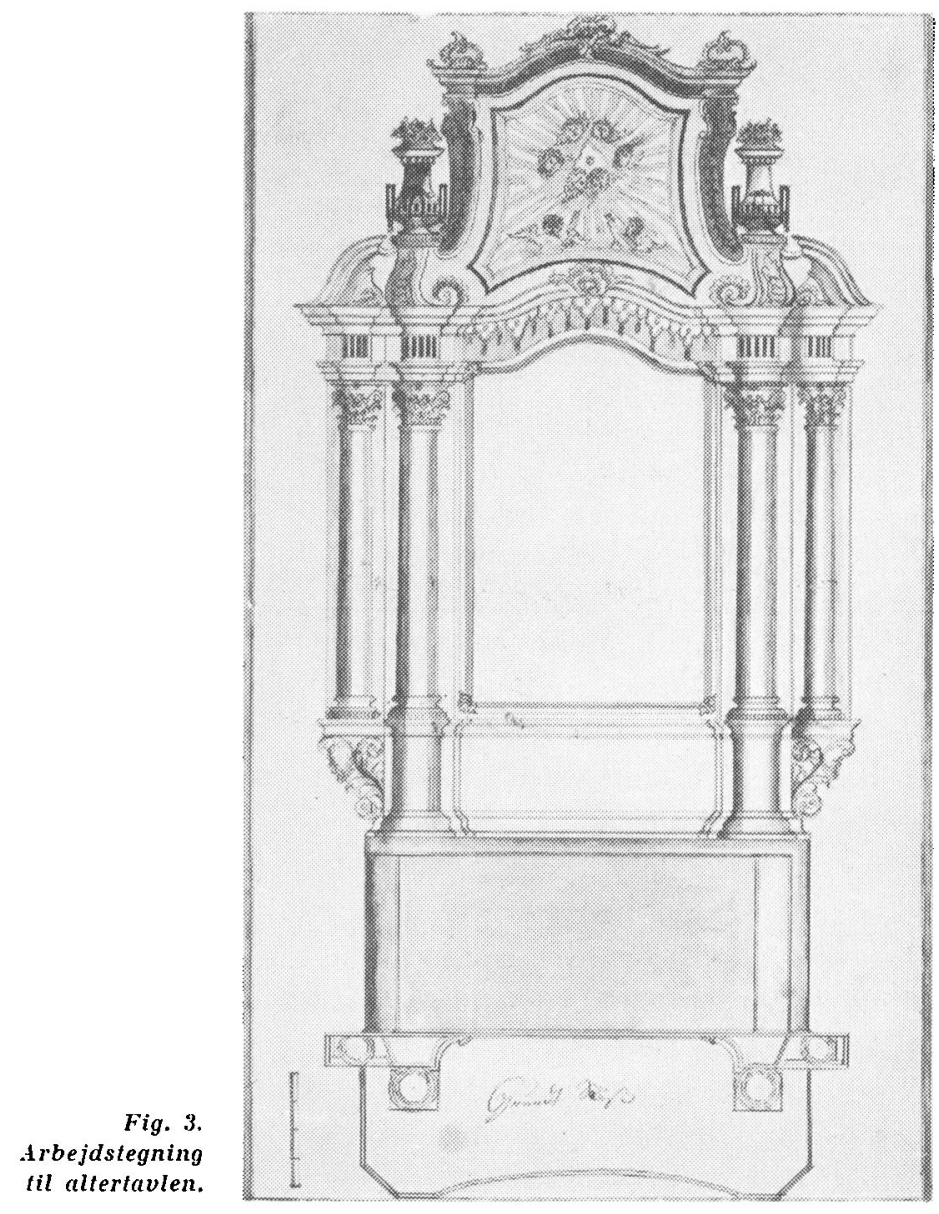

der dog er reduceret til to par. Forenklingen har især ramt tavlens. postamentparti, hvor søjlerne gennem postamentfremspringene er f $\varnothing \mathrm{rt}$ til bunds, og hermed er en renere arkitektonisk opbygning gennemf $\phi r t$.

Den altertavle ${ }^{\natural}$, der blev udf $\emptyset$ rt i 1783 , står stadig i kirken (fig. 1), og sammenlignes den med arbejdstegningen og dennes forlæg, viser det sig, at det har været nфdvendigt igen at ændre planerne, da man gik fra tegning til udforelse. 
Den f $\varnothing$ rste del af arbejdet har været nedbrydningen af Peter Petersens gamle altertavle fra 1703; på forhånd var det - som nævnt - en betingelse, at selve storfeltet og de to søjler skulle genanvendes, men under nedbrydningen har det vist sig, at endnu flere dele af den gamle altertavle kunne bruges igen, og sparsommelighed - vel snarere end pietetsfølelse - har så fået kirken til igen at ændre planerne.

Peter Petersens stil med den smuktskårne storakantus og de pluskæbede barnehoveder er så karakteristisk, at det med nogenlunde sikkerhed lader sig g $\varnothing$ re at skille de Peter Petersenske elementer ud. De er: De to hoveder på postamentfremspringene, akantusbladene på de pilastre, der flankerer storfeltet, på storstykkets og topstykkets vandrette friser, topstykkets smalle vinger og de to store blade, der vokser op fra stors $\emptyset$ jlernes kapitæler.

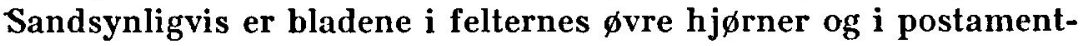
feltet også levninger af Peter Petersens akantus; måske er også topstykkets søjler fra den gamle altertavle, ligesom selve bagklædningen her kan være genanvendt, $i$ arkivalierne oplyses sáledes intet om, at det gamle topstykke skulle være beskadiget, kun at det sad løst.

Betragter man nu det endelige resultat stilistisk, bliver det klart, at de sidste ændringer har bragt altertavlen nærmere dens tilblivelsesår, 1783, forsåvidt som gavlens oval er repræsentant for en af Louis Seize-stilens yndlingsornamenter, og gitterværket her, $i$ vasernes konsoller og $i$ postamentet må sikkert også betragtes som indslag fra denne stil.

Med selve den arkitektoniske opbygning er snedker Christensen imidlertid faldet tilbage til Peter Petersens tid, og fra dennes kasserede tavle stammer - som omtalt — også den storfligede akantus.

Når man dernæst gǿr opmærksom på de rocailleagtige ornamenter om gavlens oval og nederst i storfeltets hjørner samt storfeltets snoede s $\phi j l e r$ og vingerne med de klokkeblomst-lignende ornamenter, som vel er taget fra et samtidigt ornamentstik, bliver det klart, at mester Christensen fra Sottrup i stilmæssig henseende har været en stor eklektiker.

I licitationsbetingelserne står der, at storfeltets maleri skal ud- 


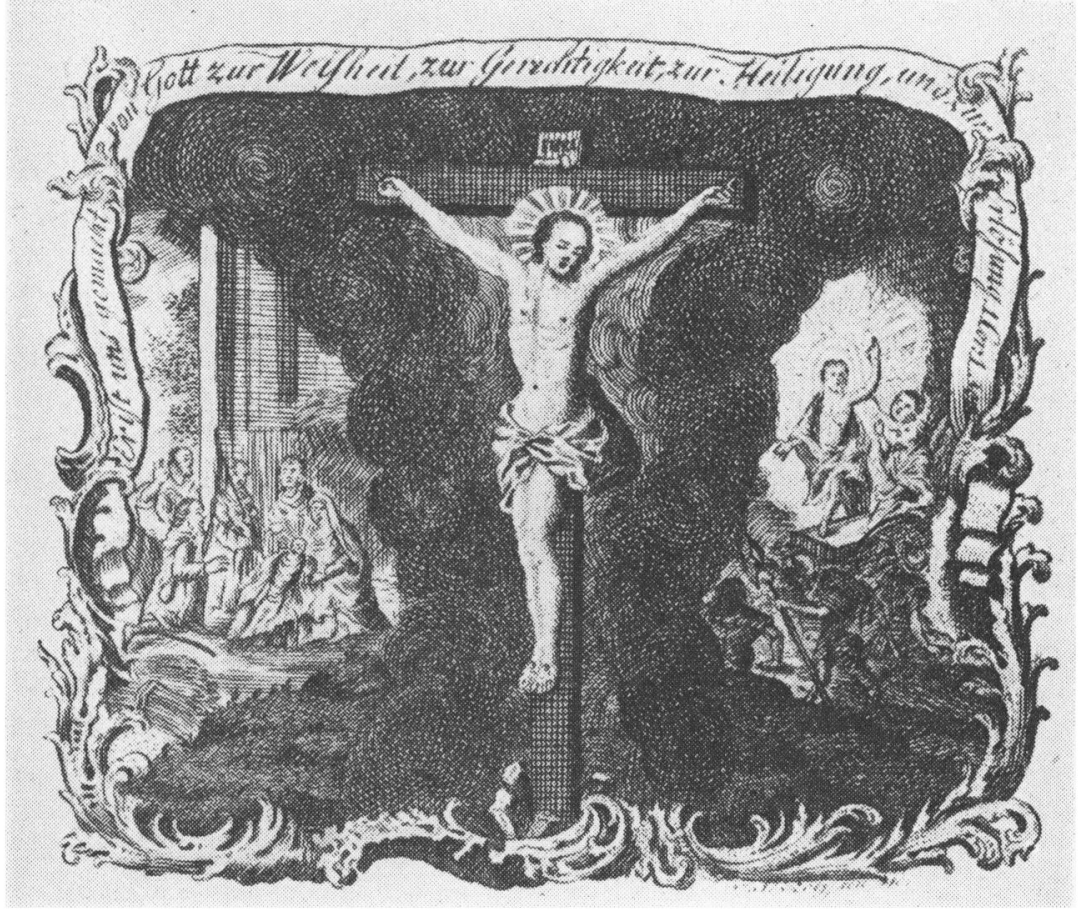

Fig. 4. Kobberstuliket forslag til altertavlemaleri.

føres »nach dem angelegten Kupfer «. Også dette kobberstik er bevaret (fig. 4), det er udf $\varnothing \mathbf{r t}$ af N. F. Rolffsen ${ }^{10}$; sandsynligvis er det stykket sammen af flere forskellige forlæg (bemærk f. eks. de to vidt forskellige Kristusfigurer) ${ }^{11}$.

Altertavlens malerier er udf $\varnothing \mathrm{rt}$ af Jes Jessen i Aabenraa'i2), if $\varnothing$ lge kirkeregnskabsbogen ${ }^{8}$ fik han 90 rigsdaler for arbejdet $i$ 1784. Han har imidlertid ikke $\varnothing$ nsket at f $\varnothing$ lge kirkens forskrifter, og i storfeltet malede han opstandelsen i stedet for korsfæstelsen.

Sottrup kirkes altertavle er et godt eksempel på, hvorledes fremstillingen af en altertavle lader sig rekonstruere ved hjælp af de bevarede arkivalier. Denne tavle er ikke skabt under en kunstners klare helhedssyn, men ved et kompromis - aff $\phi \mathrm{dt}$ af de praktiske forhold - mellem et kobberstukket forlæg til en 
rokokkotavle, en arbejdstegning med Louis Seize-indslag og dele af en barok altertavle.

\section{N O T E R}

De benyttede arkivalier findes alle i Landsarkivet i Åbenrå (L. Aa.).

1) Kildematerialet for S $\varnothing$ nderjylland i almindelighed og $\$ \phi$ nderborg amt i særdeleshed er langt fyldigere, end det normalt er tilfældet for den $\emptyset$ vrige del af landet.

2) L. Aa. S $\varnothing$ nderborg provstearkiv (f $\phi r$ 1879) : 1653-1780. Kirkeregnskabsbog for Sottrup.

3) Nærmere om snedkerdynastiet Peter Petersen i Tønder, ,Danmarks Kirker Tønder amt p. 1017, note 33.

4) L. Aa. Sønderborg kirkevisitatorium: 242. 1781-1862. Satrup Kirchengebäude c. pert., Kirchenstühle u. Gräber, Altar, Armenblock, Glocke, Schandpfahl u. versch. Bausachen.

5) L. Aa. S $\varnothing$ nderborg provstearkiv ( $f \circ \mathbf{r} 1879$ ) : Bilag til Kirkeregnskaberne for de fire glücksborgske Sogne på Sundeved. 1780, 1782.

Det tyske citat lyder i oversættelse :

På det nye alter skal der på begge sider og foroven laves nye ornamenter af nyt egetræ, hvortil en skitse in Termino skal indleveres. Ornamenterne skal forgyldes, søjlerne skal marmoreres med farver, og på tavlen skal Kristi korsfæstelse males fint og omhyggeligt efter det vedlagte kobberstik.

๑) L. Aa. 96. Sottrup præstearkiv: Ca. 1. Kirkeregnskabsbog 17811895.

7) I. G. Koenig, møbeltegner i Augsburg o. 1740 (Thieme-Becker).

8) Alle fire stik findes i Kunstindustrimuseet, København.

๑) Indberetning $19 \mathrm{om}$ altertavlen af E. Moltke i Natjonalmuseet.

10) Franz Nikolaus Rolffsen, tegner og kobberstikker, født o. 1719 i Hamburg (?) † 1802 i Hamburg. Har tegnet prospekter, planer, vignetter, mindeblade etc. (Thieme-Becker). Han har lavet et utal af kalenderstik, lejlighedsblade etc. (Hamburgisches Künstler-Lexikon), det her omtalte stik må henregnes under denne gruppe.

11) Sml. Aarb $\varnothing$ ger for nordisk Oldkyndighed og Historie 1955: Erik Moltke: Nogle malerier i vore kirker og deres forbilleder samt lidt om Peder Candid.

12) På bagsiden af postamentfeltets nadvermaleri (malet på en blyplade) står der: "Ao 1784 ist diesen Altar gantz vom Neüen gemahlt und aus-staviret worden, von Jes Jessen aus Apenrade d. 3. Septembris.*

Jes Jessen 1743-1807. Eckersbergs f $\varnothing$ rste lærer i Åbenrå (c. 1797 -1800). Malermester med kunstneriske ambitioner; hans malerier er kopier efter de store mestres værker (Weilbach). 